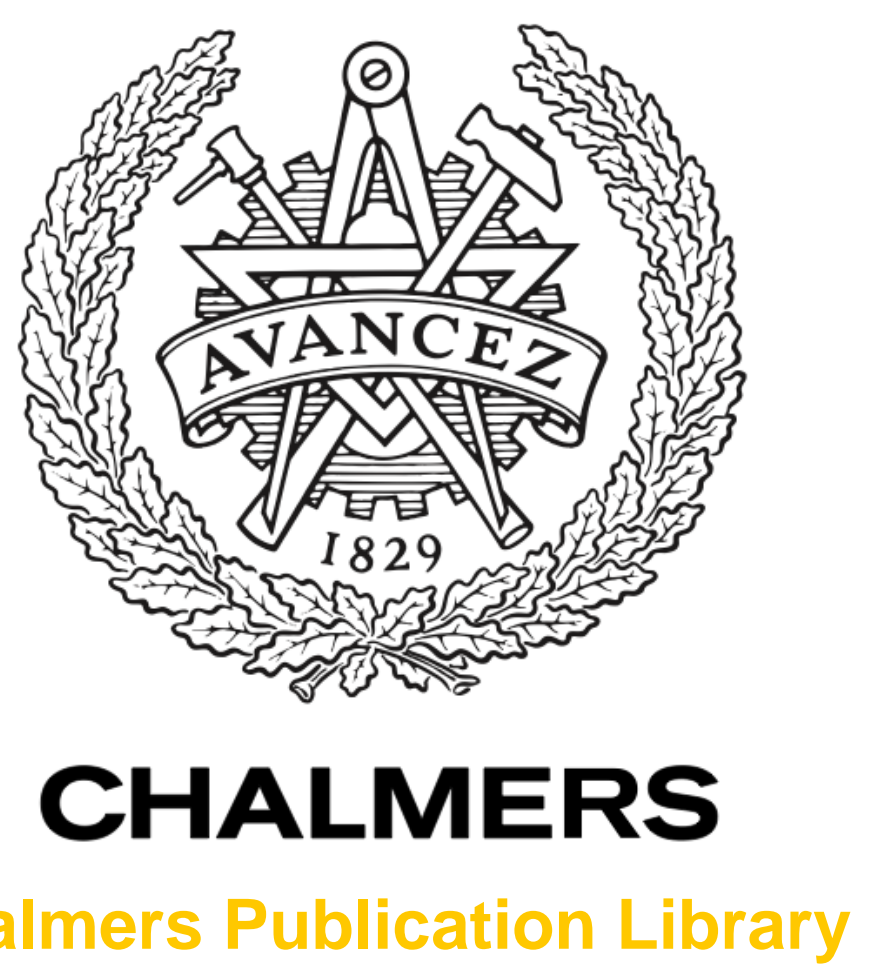

Excess attenuation for sound propagation over an urban canyon

This document has been downloaded from Chalmers Publication Library (CPL). It is the author's version of a work that was accepted for publication in:

Applied Acoustics (ISSN: 0003-682X)

Citation for the published paper:

Schiff, M. ; Hornikx, M. ; Forssén, J. (2010) "Excess attenuation for sound propagation over an urban canyon". Applied Acoustics, vol. 71(6), pp. 510-517.

http://dx.doi.org/10.1016/j.apacoust.2010.01.005

Downloaded from: http://publications.lib.chalmers.se/publication/122579

Notice: Changes introduced as a result of publishing processes such as copy-editing and formatting may not be reflected in this document. For a definitive version of this work, please refer to the published source. Please note that access to the published version might require a subscription. 


\section{Title: Excess attenuation for sound propagation over an urban canyon}

Authors: Martin Schiff ${ }^{\mathrm{a}, 1}$ (corresponding author), martin@1allyacoustics.com

Maarten Hornikx ${ }^{\text {b,2 }}$, maarten.hornikx@mech.kuleuven.be

Jens Forssén ${ }^{\mathrm{c}}$, jens.forssen@ chalmers.se

\section{Affiliations:}

${ }^{\text {a,b,c }}$ Chalmers University of Technology, Department of Civil and Environmental Engineering, Division of Applied Acoustics, SE-412 96 Göteborg, Sweden. tel +46 31772 2200, fax +46 317722212

${ }^{1}$ (Present Address) Lally Acoustical Consulting, 272 Water Street \# 5R, New York NY 10038, USA. tel +12126143280

${ }^{2}$ (Present Address) Katholieke Universiteit Leuven, Department of Mechanical Engineering, Celestijnenlaan 300, B-3001, Heverlee, Belgium. tel +32 16322643 , fax +32 16322987

\section{Abstract:}

Because quiet areas in dense urban environments are important to well-being, the prediction of sound propagation to shielded areas is an ongoing research focus. Sound levels in shielded areas (such as canyons between rows of buildings) are strongly influenced by distant sources, so propagation factors such as metrology, screening, and intermediate canyons (occurring between a source canyon and a receiver canyon) must therefore be addressed in an engineering propagation model. Though current models address many important propagation factors, engineering treatment of a closed urban canyon (subject to multiple internal reflections) remains difficult.

A numerical investigation of sound propagation across the open tops of intermediate urban canyons has been performed, using the parabolic equation and equivalent sources methods. Results have been collected for various canyon geometries, and the influence of multiple canyons, canyon/rooftop absorption, variable rooftop height, wind gradient, and correlated versus uncorrelated source models have been investigated. Resulting wideband excess attenuation values ranged from -1 to $-4 \mathrm{~dB}$ per canyon, and were fairly constant with frequency in many useful cases. By characterizing the excess attenuation of canyons intermediate to the source and receiver, the influence of these intermediate canyons could be addressed simply, without the overhead of a detailed numerical calculation. Keywords: Parabolic equation method; Equivalent sources method; Outdoor sound propagation; Urban canyon; Traffic noise. (PACS: 43.28.En, 43.28.Js) 
Environmental noise continues to be one of the most common quality-of-life complaints in many cities. Because of the difficulty of sufficiently reducing noise levels in directly exposed outdoor locations [1], a complementary strategy is to design dwellings with access to a "quiet side" — a sufficiently quiet courtyard or backyard that is shielded from direct noise exposure [2].

Despite being accurate for directly exposed and simply screened locations, current prediction methods (such as Harmonoise [3] or Nord2000 [4]) often fail to accurately predict immission in shielded areas subject to multiple reflections, such as a courtyard screened on all sides. Thorsson et al. [5] found errors of 11 to $14 \mathrm{~dB}$ when comparing measured and predicted noise levels in such a courtyard, while a similar comparison at a location directly exposed to traffic yielded good agreement.

Recent research has turned instead to using sophisticated numerical methods to evaluate sound propagation. Using the simplified geometry of urban canyons formed by buildings, streets, and yards, these numerical methods can feasibly be used to evaluate propagation within or between canyons, while including important factors such as multiple reflections, diffraction, absorption, scattering, and atmospheric effects (see, for example, urban canyon studies using the Equivalent Sources Method by Ögren and Kropp [6], and using the Finite Difference Time Domain model coupled with the Parabolic Equation model by van Renteghem, Salomons, and Botteldooren [7]). Applying these accurate methods over wide and complex urban areas, however, remains computationally prohibitive.

Because a range of receiver locations may be influenced by the same wide source distribution, time-averaged shielded-side community noise levels are often nearly constant across a wide urban area. Thorsson et al. [5] illustrated this with field measurements, and proposed a simple "flat city" engineering model for shielded noise immission. In this type of model, source and receiver points are raised to equivalent sources and receivers at roof level; immission is calculated from the source strength, propagation over flat, hard ground, and a series of correction factors. Each correction factor represents a single propagation loss factor: the coupling from source to roof level, surface influence, meteorological effects, and the coupling from roof level to shielded receiver. Although Thorsson et al. identified a number of possible individual correction factors, their study instead utilized an overall empirical correction based on field-measured data [5].

In such an engineering model, intermediate canyons that lie between a source canyon and a receiver canyon could be included as a surface influence propagation loss factor, since they represent a significant departure from the 
smooth ground or simple screening assumed in many engineering methods. For instance, although the Harmonoise model allows for diffractive screening by barriers and Fresnel-weighting of ground attenuation for arbitrary locallyreacting ground impedance [3], the model overlooks multiple reflections between barriers or within canyons.

Knowledge of the influence of these intermediate canyons on long-range sound propagation would be useful to estimate shielded-side noise immission, without the significant computational effort of a detailed numerical calculation. The goal of this paper is therefore to characterize the wide-band "insertion loss" of one or more urban canyons, for the case of grazing sound propagation between a roof-level source and receiver.

\section{Tools of analysis}

Several numerical methods are suitable for exploring the influence of urban canyons on sound propagation. In the current work, the parabolic equation and equivalent sources methods were used as a basis for analysis and validation of results. The following describes the concepts and assumptions of each method; rigorous treatments of both methods are available in the references [6][8][9].

\subsection{Parabolic equation method}

In atmospheric acoustics, the Parabolic Equation (PE) method is a versatile numerical method for calculating sound propagation from a monopole point source over a ground surface of arbitrary impedance. In the current work, the Crank-Nicholson PE formulation given by Salomons [8] was used, based on the one-way axisymmetric Helmholtz equation. Using $r-z$ coordinates and $\exp (-j \omega t)$ time dependence, we have

$$
\left[\frac{\partial}{\partial r}-j k \sqrt{1+L}\right] q=0 ; \quad L=\frac{1}{k^{2}}\left[\frac{\partial^{2}}{\partial z^{2}}\right],
$$

where $k$ is the wave number and the complex amplitude $q(r, z)$ is related to the complex sound pressure amplitude $p(r, z)$ by $q=p \sqrt{r}$. Height-varying sound speed (from wind or temperature gradients) can be incorporated via an effective wave number $k_{\text {eff }}=\omega / c_{\text {eff }}$, where $c_{e f f}$ (the adiabatic sound speed plus any wind velocity component) can vary with height. A rational-linear approximation of the square-root operator in Eq. (1) is used in Salomons' solution, resulting in an accurate propagation relation for angles within approximately $\pm 35^{\circ}$ from horizontal.

The resulting parabolic equation is solved by approximating each derivative with a centered second-order accurate finite difference. This leads to a set of linear equations, with one equation for each height point; solving this system numerically leads to an expression for a single PE range step, $q(r) \rightarrow q(r+\Delta r)$. The sound field grid is 
thereby "marched" in the direction from source to receiver as detailed in [8], and therefore excludes any

backscattering or other backwards propagation. Consistent results can be assured at a grid discretization (height and range step) of about $\lambda / 10$ (one-tenth wavelength), as used throughout the current work.

This PE method characterizes sound propagation only over flat ground and only in one direction. In the current work, Kirchhoff and complementary Kirchhoff approximations were made at each rooftop edge and canyon wall. At a rooftop edge, the domain is extended downward into the canyon, with grid points along the canyon wall set to zero- the Kirchhoff approximation. For canyon reflections, the complementary approximation is used: the grid values up to the roofline of the canyon wall are reduced by a reflection factor, and the values above the roofline are set to zero. This approach has been validated for screening [10] and multiple reflections [11], though it may be less accurate for receivers very near to or at high elevation angles from the diffraction point.

\subsection{Equivalent sources method}

The arrangement of a road between two buildings lends itself to a two-dimensional model, where the road traffic acts as a continuous line source and the buildings form a continuous canyon. The 2-D Equivalent Sources Method (ESM) as applied to the canyon geometry by Ögren and Kropp [6] simplifies this domain by splitting it into two simpler domains with known Green's functions: that of propagation over a flat surface (a Hankel function), and that of the sound field inside a closed rectangular cavity (a modal summation). An array of equivalent sources at both sides of the interface is used to marry the two sub-domains, forming a continuous overall sound field as illustrated in Fig. 1.

The equivalent source strengths fulfill the Helmholtz equation as well as continuity of pressure and normal velocity at the interface. The system can be formed into a set of linear equations by discretizing the equivalent source distribution, allowing solution for the equivalent source strengths. In [9], Hornikx and Forssén extended the 2-D ESM to a "2.5-dimensional" geometry; that is, a geometry that is still invariant in the y-direction, but producing a 3-D point source solution of the Helmholtz equation, which also can be used to obtain an incoherent line source solution.

\section{Model validation}

In this section, we compare the excess attenuation (EA) of a canyon in a rooftop among the numerical models introduced above. We define this excess attenuation to be the difference in receiver sound pressure level between the case with the canyon present and the case without the canyon present (i.e. a flat, continuous roof). 


\subsection{ESM versus PE}

To validate the PE-Kirchhoff method for this problem, a simple case was chosen for analysis in the ESM, which has been previously validated for the canyon geometry [2][6]. Initially, a 2-D ESM was used; the 2.5-D ESM result is compared below in section 3.2. The comparison was performed for the geometry shown in Fig. 2: source and receiver at roof level, $200 \mathrm{~m}$ apart, with a $20 \mathrm{~m}$ x $20 \mathrm{~m}$ canyon located in the center of the field. All roof and canyon surfaces are perfectly reflecting. The ESM-calculated excess attenuation arising from this arrangement is shown in Fig. 3. In the figure, 1/3-octave band values are superimposed over the narrow-band results, which were generated for 20 frequencies within each 1/3-octave band from $50 \mathrm{~Hz}$ up to $4 \mathrm{kHz}$ (a range appropriate for urban traffic noise). As shown in the figure, the narrowband excess attenuation oscillates widely due to interference among multiple reflections within the canyon. However, the 1/3-octave band values all lie close to their mean value of $-1.7 \mathrm{~dB}$ (that is, the simple arithmetic average of the 1/3-octave band EA values), with a standard deviation of $0.17 \mathrm{~dB}$ and no clear pattern of frequency dependence. Because of this relative invariance with frequency, the A-weighted excess attenuation $\mathrm{Awt}_{\mathrm{Ctr}}$ (calculated against the transportation noise spectrum Ctr of ISO 717-1 [12]) has a similar value of $-1.8 \mathrm{~dB}$.

Next, this arrangement was analyzed using the PE method, first with 30 total reflections within the canyon (in excess of the 25 reflections validated for hard obstacles by Aballéa and Defrance [11]); the result is shown in Fig. 4. On a 1/3-octave band basis, this result was nearly identical to the ESM result in Fig. 3, with slightly less narrowband oscillation due to the finite reflection order. This result motivates use of the computationally-efficient PE for this configuration.

To further examine the influence of reflection order on this agreement, analysis was performed with no reflections, or the case of simple diffraction over both canyon edges. This case also corresponds approximately to that of total sound absorption within the canyon. The result appears in Fig. 5; in this figure, the oscillation around the average is eliminated, leaving a nearly constant narrowband spectrum. The $1 / 3$-octave band spectrum is also nearly constant, with an average value and $\mathrm{Awt}_{\mathrm{Ctr}}$ value of $-1.8 \mathrm{~dB}$, the same as was found with 30 reflections and similar to the ESM result.

These results suggest that on both a 1/3-octave band and an A-weighted basis, the canyon excess attenuation is virtually independent of the number of canyon reflections included in the calculation. Considered another way, it indicates that canyon attenuation is independent of the canyon interior absorption, since absorption is not considered 
in a 0 -reflection analysis. This is in contrast to the analysis of the sound field within a source or receiver canyon, where surface properties must be considered for accurate results [2][7][13][14].

\subsection{Influence of source model}

The PE method describes propagation from a point source in an axisymmetric domain, while the ESM describes a coherent line source in a 2-D domain. However, a finite incoherent line source is a more accurate model for traffic noise emission from a finite roadway; it has been shown that using a coherent or an infinite incoherent source model can be overly optimistic when evaluating noise control measures [9].

A sample calculation was made for a $400 \mathrm{~m}$ long incoherent line source, according to the formulation in [15]. In this comparison, the 1/3-octave band excess attenuation of the canyon did not differ significantly among the different source models. The average 1/3-octave value for the finite incoherent ESM differed by only $0.04 \mathrm{~dB}$ from both the coherent ESM and the zero-reflection PE results, with similar frequency independence and similar deviation in individual values about the average (standard deviation of $0.17 \mathrm{~dB}$ for the coherent versus $0.11 \mathrm{~dB}$ for the finite incoherent).

\section{$4 \quad$ Parameter study}

Since the efficient 0-reflection PE method agrees well with the ESM method and the finite incoherent line source model for the current problem, it was used in nearly all the remaining parameter analyses. The influence of geometric parameters such as canyon depth, width, location, and quantity were evaluated for typical urban canyon geometries and distance scales. Variation in source/receiver height, roof height, roof impedance, and wind gradient were then evaluated for typical cases.

\subsection{Canyon depth}

The influence of canyon depth was examined first. Using the geometry in Fig. 2, the analysis was repeated using canyon depths of $8 \mathrm{~m}$ and $40 \mathrm{~m}$ (approximately 2 story and 10 story buildings, respectively). These results are summarized in Table 1, again in terms of the mean 1/3-octave band and $\mathrm{Awt}_{\mathrm{Ctr}}$ values. In each case, 1/3-octave band values remained fairly constant about the average (still -1.8 dB in each case), especially for greater canyon depths. For canyons having very shallow depth compared to the width, reflections from the canyon bottom will begin to influence the results; however, such wide, shallow canyons may not be of high practical relevance. 


\subsection{Canyon width and location}

Next, variation in the width and location of a single canyon between the source and receiver was investigated. The results of 20 such trials are summarized in Table 2. In almost every case, the resulting EA spectrum was nearly constant on a wide band basis; standard deviation in the 1/3-octave band values was less than $0.1 \mathrm{~dB}$ in all but one geometry (where the receiver was very close to the canyon). In all cases, the A-weighted EA was within $0.1 \mathrm{~dB}$ of the mean 1/3-octave band EA.

In evaluating these results, it was found that the average 1/3-octave band value depends not on the absolute canyon width, but on the width relative to the overall source-receiver distance: calculations with a constant ratio of canyon width to field distance (yet different absolute widths) yielded nearly the same excess attenuation. Figure Fig. 6 is a scatter plot of nine such PE method results, showing the average 1/3-octave band excess attenuation versus the normalized canyon width (for a constant normalized canyon center location of 0.5 , or exactly midway between source and receiver). These data represent absolute canyon widths from $10 \mathrm{~m}$ to $40 \mathrm{~m}$ and absolute field distances from $100 \mathrm{~m}$ to $300 \mathrm{~m}$. As shown in the figure, the excess attenuation varied between $-1.3 \mathrm{~dB}$ and $-3.0 \mathrm{~dB}$. The tight group of points at the normalized widths of 0.2 and 0.1 (three points each) illustrates the results of calculations with different absolute widths, but identical normalized widths.

Similarly, the average excess attenuation value depends not on the absolute source-canyon distance, but on the canyon location relative to the total source-receiver distance. Calculations with the same ratio of source-canyon distance to overall field distance yielded nearly the same average 1/3-octave band result, as shown in Fig. 7 for eleven PE calculations (all with a normalized canyon width of 0.1). These data represent absolute canyon center locations from $31 \mathrm{~m}$ to $189 \mathrm{~m}$ from the source, and absolute field distances from $100 \mathrm{~m}$ to $300 \mathrm{~m}$. Excess attenuation ranged from $-1.8 \mathrm{~dB}$ to $-4.7 \mathrm{~dB}$, and the tight grouping (three points at location 0.5 and two points at location 0.675 ) shows similar results for calculations with the same normalized canyon location. The symmetry of the result about the center location 0.5 illustrates the expected reciprocity between source and receiver.

These figures illustrate some general trends in the excess attenuation for an urban canyon. As canyon width increases in comparison to the total source-receiver distance (Fig. 6), the effect of the canyon increases in a fairly linear fashion. Likewise, as the canyon moves closer to the source or receiver (Fig. 7), its effect increases.

It should be noted that the results in Fig. 7 were generated using the PE method, but the Kirchhoff approximation may lead to inaccurate results for receivers very close to the canyon edge. Reproducing the situation 
of a receiver $1 \mathrm{~m}$ from the edge of a $20 \mathrm{~m}$ wide canyon in a $200 \mathrm{~m}$ field using the ESM, the average 1/3-octave band ESM result of $-3.7 \mathrm{~dB}$ (not a product of the Kirchhoff approximation) was significantly different than the PE result of $-4.7 \mathrm{~dB}$. This confirms that the Kirchhoff approximation used in the PE method may be less accurate for receiver locations very close to the diffraction point.

\subsection{Multiple canyons}

All of the previous results were obtained for a single canyon in a flat rooftop. It is not immediately obvious whether inserting additional canyons in this rooftop will result in an overall effect that is the simple sum of the influences of each individual canyon; nor can it be taken for granted that the "0-reflection" diffraction-only PE calculation scheme remains accurate for multiple canyons.

To investigate this, calculations were made for a single canyon located eccentrically in a $200 \mathrm{~m}$ field, and this result was compared with a calculation including an identical second canyon in the reciprocal location. Reciprocity between source and receiver suggests that the two canyons should have identical individual influence. The results of this trial are summarized in Table 3; the result with both canyons produced an A-weighted and an average 1/3-octave band EA of -3.9 dB — approximately double the single-canyon value of $2.0 \mathrm{~dB}$.

A larger comparison in a $400 \mathrm{~m}$ field was then undertaken comparing the result from each of four individual canyons to a trial including all four together, as well as to a trial including all four along with their four reciprocal canyons (for a total of eight canyons). These results are summarized in Table 4. The four-canyon EA of -6.0 dB is within $0.4 \mathrm{~dB}$ of the EA sum of the individual canyons, with a similar agreement for the A-weighted values. Including the four reciprocal locations for a calculation over a total of eight canyons, the result of $-12 \mathrm{~dB}$ is within $1 \mathrm{~dB}$ of the EA sum of the individual canyons on both a 1/3-octave band and an A-weighted basis.

\subsection{Source and receiver height}

Each of the prior results was calculated for a source and receiver exactly at roof level—the configuration most relevant to propagation over canyon openings. However, real sources and receivers may not always lie exactly at roof level; for instance, the case of noise emission from ventilation equipment mounted on structure over a rooftop. When both source and receiver are elevated, significant frequency dependence is expected due to interference between the direct and reflected waves (the "interference dip"). However, to the extent that the frequency dependence of the canyon result matches the frequency dependence with no canyon, the result "re no canyon" could still be nearly constant, even if the result "re free field" shows significant variation with frequency. 
To illustrate this, Fig. 8 shows the results for a source and receiver elevation of $4 \mathrm{~m}$, again for the case of a single $20 \mathrm{~m}$ x $20 \mathrm{~m}$ canyon in the center of a $200 \mathrm{~m}$ field. Two separate regions can be identified in the spectrum. In low frequencies, up to about $500 \mathrm{~Hz}$ (i.e. below the first interference dip), the canyon influence was nearly constant at about -1.8 dB in each 1/3-octave band-the same result as was obtained for source and receiver at roof level. For higher frequencies, near the region of each interference dip, the result relative to the no-canyon case becomes very high, since the flat ground interference minimum is disturbed by the presence of the canyon.

With a lower source and receiver height, the frequency of the first interference dip is higher, and a wider frequency range of near-constant wideband results can be expected. At a source and receiver height of $1 \mathrm{~m}$, the frequency of the first interference dip (approximately $17 \mathrm{kHz}$ ) would be well above the frequency range of interest-a result that holds regardless of the canyon location in the field.

\subsection{Roof height}

To better represent realistic variation in real building profiles, the presence of a change in roof height was investigated next. In such an arrangement, the different roof levels eliminate the direct line-of-sight path from source to receiver, as shown in Fig. 9.

First, a $4 \mathrm{~m}$ increase in roof height across the canyon was investigated, with other geometry aspects remaining as in Fig. 2. The results relative to the no-canyon case are plotted in Fig. 10. In this case, the reference "no canyon" field is that of a flat roof with a $4 \mathrm{~m}$ jump in roof height at $r=110 \mathrm{~m}$ (the location of the far canyon wall), with source and receiver at their respective roof heights, as shown in the lower half of Fig. 9. This reference field was computed using the same PE method used for the canyon case.

The results in Fig. 10 are near zero across all bands, and especially so at higher frequencies. The canyon has little influence on the receiver level, compared to the screening effect of the $4 \mathrm{~m}$ jump in roof height (which alone provides increasing attenuation with frequency).

In contrast, the results with a $1 \mathrm{~m}$ roof height difference clearly show the influence of the canyon, as illustrated in Fig. 11. In low frequencies, the canyon influence is $-1.8 \mathrm{~dB}$, the same as with constant roof height. As the frequency increases, the influence remains close to zero, as was seen with the $4 \mathrm{~m}$ roof jump; as the wavelength shortens in comparison to the $1 \mathrm{~m}$ height difference, the screening effect begins to dominate. 


\subsection{Roof impedance}

Real roof structures likely provide some finite impedance. Since the acoustic impedance of common roof constructions has not been widely studied, a real normalized impedance $\left(Z_{n}\right)$ of 78 was used as an approximation, corresponding to an absorption coefficient $(\alpha)$ of 0.05 for normal incidence. Fig. 12 shows the result of a trial using the geometry of Fig. 2 with a hard canyon but finite roof impedance. In this case, the reference calculation comprises an impedance roof with a 20 m hard strip replacing the canyon; the hard strip is included so that the absorption profile is consistent, since the canyon floor is also taken to be hard. The results reach $-1.7 \mathrm{~dB}$ across the low frequency range, similar to a canyon in a hard roof. Some shifting of high frequency values is apparent, possibly due to diffraction at the boundaries of the hard strip in the reference case.

\subsection{Downwind propagation}

Thus far, all calculations were performed for a non-moving atmosphere with no temperature gradient, precluding the effects of atmospheric refraction. Since downwind refraction can result in higher received levels, calculations including a downwind gradient are of interest. The results in Fig. 13 correspond to a logarithmic downwind profile with a nominal wind speed of $10 \mathrm{~m} / \mathrm{s}$ at $10 \mathrm{~m}$ height, using the geometry in Fig. 2 and a hard roof surface. The sound speed used varies with height according to

$c(z)=c_{0}+b \ln \left(z / z_{0}\right)$

with the adiabatic sound speed $c_{0}$ taken as $343 \mathrm{~m} / \mathrm{s}$; the constant $b=2.171 \frac{\mathrm{m}}{\mathrm{s}}$ determined from the given velocity of $10 \mathrm{~m} / \mathrm{s}$ at $10 \mathrm{~m}$ height; and the characteristic roughness $z_{0}$ taken as $0.1 \mathrm{~m}$. This effective sound speed approach is accurate for propagation angles of less than 20 degrees [10].

These results, which represent the excess attenuation compared to flat ground with wind, show the familiar constant $-1.8 \mathrm{~dB}$ value in the first several low-frequency bands, with erratic but much greater attenuation above $200 \mathrm{~Hz}$. Fig. 14 presents the results using the same configuration, but for a reduced downwind speed of $4.6 \mathrm{~m} / \mathrm{s}$ at $10 \mathrm{~m}$ height; with more moderate wind speed, this result shows the regular $-1.8 \mathrm{~dB}$ wideband value up to500 $\mathrm{Hz}$.

Both of these calculations showed erratic results in higher frequencies, with increased wind speed lowering the frequency boundary between constant and more erratic attenuation. This effect is likely due to the refractive "trapping" of higher-frequency waves near the ground surface: the logarithmic wind profile produces a steep gradient near the ground-level source-receiver line, yielding more multiple-reflection refracted paths between source 
and receiver at higher frequencies. The presence of the canyon interferes with some of these refracted paths, producing lower and less regular receiver levels at high frequencies. Inclusion of effects such as ground scattering, ground absorption, and turbulence would serve to moderate this trapping of ground-level waves, and may produce more realistic results in refractive conditions.

\section{Conclusion}

Calculations using the parabolic equation and equivalent sources methods showed that, under many circumstances, intermediate urban canyons have a consistent, attenuating influence on propagation between rooflevel sources and receivers. The resulting excess attenuation ranged from $-1 \mathrm{~dB}$ to $-4 \mathrm{~dB}$ per canyon, on both a 1/3-octave band and an A-weighted basis. On a wide frequency-band basis, this attenuation is often nearly constant with frequency. This influence appears to be independent of the interior properties of the canyon; only parameters such as canyon width and field location prove to be significant. It can therefore be predicted using an efficient application of the parabolic equation method, in which interior canyon reflections are neglected in favor of diffraction at the edges of the canyon opening.

Additional conclusions can be drawn from the results of the parameter study. For realistic canyon depths (the current work studied depth-to-width ratios exceeding 4:10), the excess attenuation does not depend significantly on canyon depth. For source and receiver lifted up from the roof plane, the attenuation is largely unchanged up to around half the frequency of the first interference dip. Calculations including finite roof impedance indicate that the results are not very sensitive to impedance value. Trials with up to eight canyons indicate that the total attenuation of multiple canyons can be estimated with reasonable accuracy as a sum of the individual canyon attenuation values. With variations in roof height that result in significant screening between source and receiver, the screening influence strongly dominates the canyon influence (except at the lowest frequencies where the screening effect is weak). Finally, the current methods are sensitive to meteorological refraction effects, with erratic results at high frequencies under downward-refracting conditions.

Concerning future work, the attained results could contribute to a data set characterizing the attenuation of intermediate urban canyons, which could form a propagation loss factor within the framework of a more general engineering method such as the "flat city" model of Thorsson et al. [5]. Further results are however needed before such an engineering method could be considered complete; for example, an expanded study on the effect of 
combined variations of canyon width and canyon location. Further study of the effect of wind and temperature gradient on the canyon effect is also needed, both for propagation over canyons, and from canyon to canyon. 


\section{References}

[1] Kihlman T, Kropp W. City traffic noise - a local or global problem? Noise Control Engineering Journal 2001; 49(4):165-169.

[2] Hornikx M. Sound propagation to two-dimensional shielded urban areas-a numerical and scale model study of façade treatments (Licentiate Engineering thesis). Göteborg, Chalmers University of Technology, 2006.

[3] van Maercke D, Defrance J. Development of an analytical model for outdoor sound propagation within the Harmonoise project. Acta Acustica - Acustica 2007; 93:201-212.

[4] Jonasson HG, Storeheier SÅ. Nord 2000: New Nordic prediction method for road traffic noise. SP Swedish National Testing and Research Institute, SP Report 2001:10, 2001.

[5] Thorsson PJ, Ögren M, Kropp W. Noise levels on the shielded side in cities using a flat city model. Applied Acoustics 2004; 65(4):313-323.

[6] Ögren M, Kropp W. Road traffic noise propagation between two dimensional city canyons using an equivalent sources approach. Acta Acustica - Acustica 2004; 90:293-300.

[7] van Renterghem T, Salomons E, Botteldooren D. Parameter study of sound propagation between city canyons with a coupled FDTD-PE model. Applied Acoustics 2006; 67(6):487-510.

[8] Salomons EM. Computational atmospheric acoustics. Dordrecht, Kluwer Academic Publishers, 2001.

[9] Hornikx M, Forssén J. The 2.5-dimensional equivalent sources method for directly exposed and shielded urban canyons. Journal of the Acoustical Society of America 2007; 122(5):2532-2541.

[10] Salomons EM. Diffraction by a screen in downwind sound propagation: a parabolic equation approach. Journal of the Acoustical Society of America 1994; 95(6):3109-3117.

[11] Aballéa F, Defrance J. Single and multiple reflections in plane obstacle using the parabolic equation method with a complementary Kirchhoff approximation. Acta Acustica - Acustica 2007; 93:22-30.

[12] ISO 717-1:1996. Acoustics - Ratings of sound insulation in buildings and of building elements - Part 1: Airborne sound insulation. Geneva, International Organization for Standardization, 1996. 
[13] Ögren M. Prediction of traffic noise shielding by city canyons (PhD thesis). Göteborg, Chalmers University of Technology, 2004.

[14] Kihlman T, Ögren M, Kropp W. Prediction of urban traffic noise in shielded courtyards. Dearborn, Internoise 2002 proceedings, 2002.

[15]Hornikx M, Forssén J. Noise abatement schemes for shielded canyons. Applied Acoustics 2009; 70(2):267-283. 


\section{Vitae:}

Martin Schiff is a partner at Lally Acoustical Consulting in New York City. He holds a M.Sc. in Sound \& Vibration at Chalmers University of Technology in Sweden, where his research topics included outdoor sound propagation in cities and noise prediction for large wind turbines. Martin additionally holds a B.Sc. in Mechanical Engineering from the University of Texas at Austin, and has over 12 years' work and research experience in acoustics and engineering.

Maarten Hornikx is a post-doctoral researcher in the Department of Mechanical Engineering at Katholieke Universiteit Leuven in Belgium. He holds a Ph.D. in Acoustics from the Department of Civil and Environmental Engineering at Chalmers University of Technology in Sweden, along with a M.Sc. degree in Architecture, Building and Planning from the Eindhoven University of Technology, the Netherlands. His primary research interests are in modeling atmospheric and urban sound propagation.

Jens Forssén is an Associate Professor of Applied Acoustics at Chalmers University of Technology in Sweden. He holds a Ph.D. in acoustics at the Department of Civil and Environmental Engineering at Chalmers, and a Masters degree in Engineering Physics. After the Ph.D. in 2001 he had two postdoctoral periods abroad: one at Salford University, UK, and one at Ecole Centrale de Lyon, France. His primary research interest is within outdoor sound propagation and community noise. Within this field he has studied effects of terrain and meteorology, mainly in development of numerical tools, with a special interest in urban acoustics. 


\section{Figures:}

Fig. 1. Splitting of the domain in the ESM.

Fig. 2. Initial source/receiver/canyon geometry.

Fig. 3. ESM result, geometry as Fig. 2. Avg = average 1/3-octave band (1/3-O.B.) $\Delta \mathrm{L}_{\mathrm{p}}$ value; $\sigma=$ standard deviation in 1/3-O.B. $\Delta \mathrm{L}_{\mathrm{p}}$ values; Awt $\mathrm{Ctr}=\mathrm{A}$-weighted overall value based on ISO 717-1 Ctr spectrum

Fig. 4. PE result, 30 reflections, geometry as Fig. 2.

Fig. 5. PE result, 0 reflections, geometry as Fig. 2.

Fig. 6. Average 1/3-octave band EA versus the canyon width, normalized by the total field length. Normalized canyon center location of 0.5 throughout.

Fig. 7. Average 1/3-octave band EA versus the canyon center location, normalized by the total field length. Normalized canyon width of 0.1 throughout.

Fig. 8. PE result, 0 reflections within canyon. Source and receiver $4 \mathrm{~m}$ above roof level, otherwise geometry as Fig. 2.

Fig. 9. The modeled roof-height difference.

Fig. 10. PE result, 0 reflections. Receiver roof level $4 \mathrm{~m}$ higher than source roof level; otherwise geometry as Fig. 2.

Fig. 11. PE result, 0 reflections. Receiver roof level $1 \mathrm{~m}$ higher than source roof level; otherwise geometry as Fig. 2.

Fig. 12. PE result, 0 reflections. Rooftop $Z_{n}=78$, otherwise geometry as Fig. 2. In reference, hard roof strip replaces hard canyon bottom.

Fig. 13. PE result, 0 reflections. Downwind, log-profile with $10 \mathrm{~m} / \mathrm{s}$ at $10 \mathrm{~m}$ height, otherwise geometry as Fig. 2. Reference case includes wind.

Fig. 14. PE result, 0 reflections. Downwind, $\log$ profile with $4.6 \mathrm{~m} / \mathrm{s}$ at $10 \mathrm{~m}$ height, otherwise geometry as Fig. 2. Reference case includes wind. 


\section{Tables:}

Table 1

Canyon EA with varying canyon depth (other geometry as Fig. 2).

Table 2

Canyon EA with varying canyon width, location, and overall field length.

Table 3

Canyon EA combining two reciprocal canyons. $200 \mathrm{~m}$ field length.

Table 4

Canyon EA for combinations of up to eight reciprocal canyons. $400 \mathrm{~m}$ field length. 


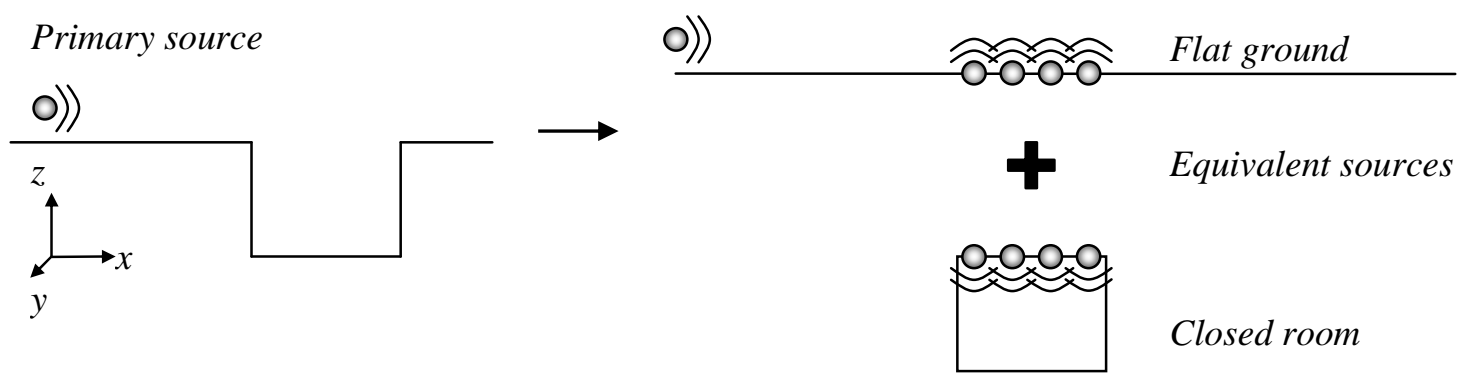

FIGURE 1 


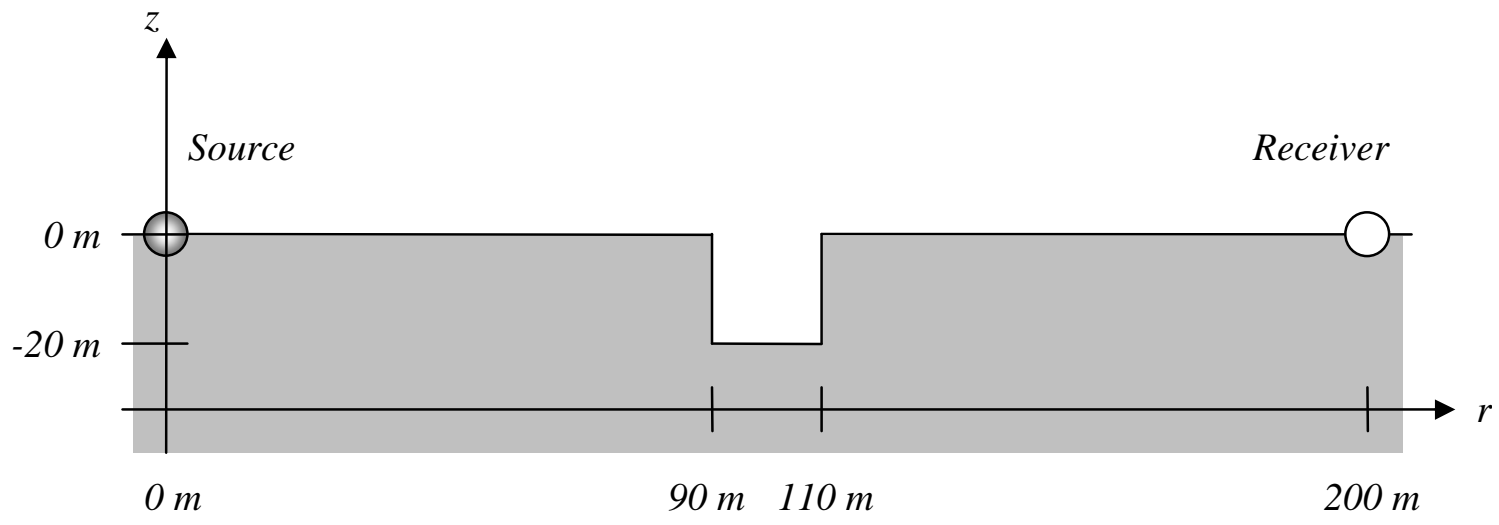

FIGURE 2 


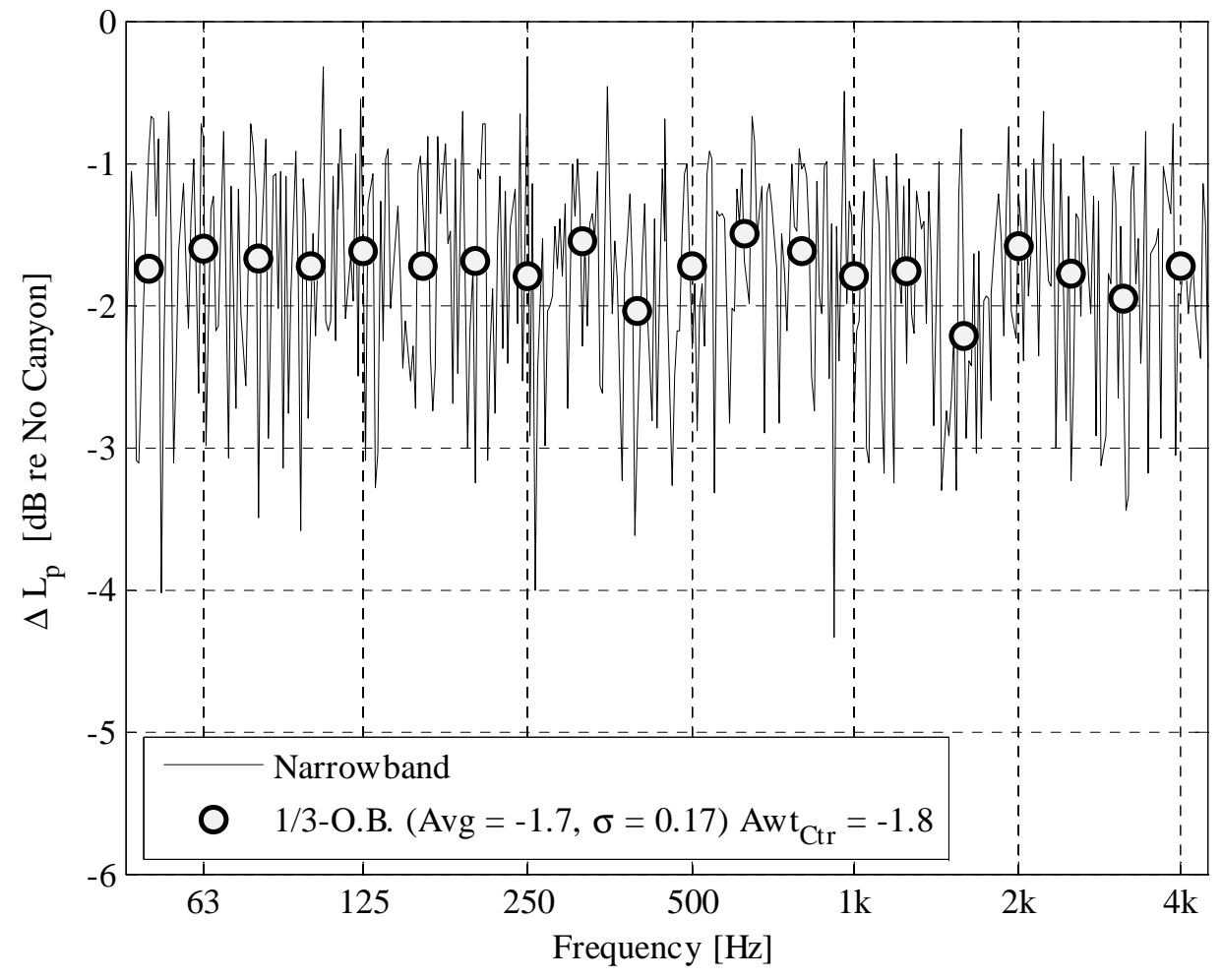

FIGURE 3 


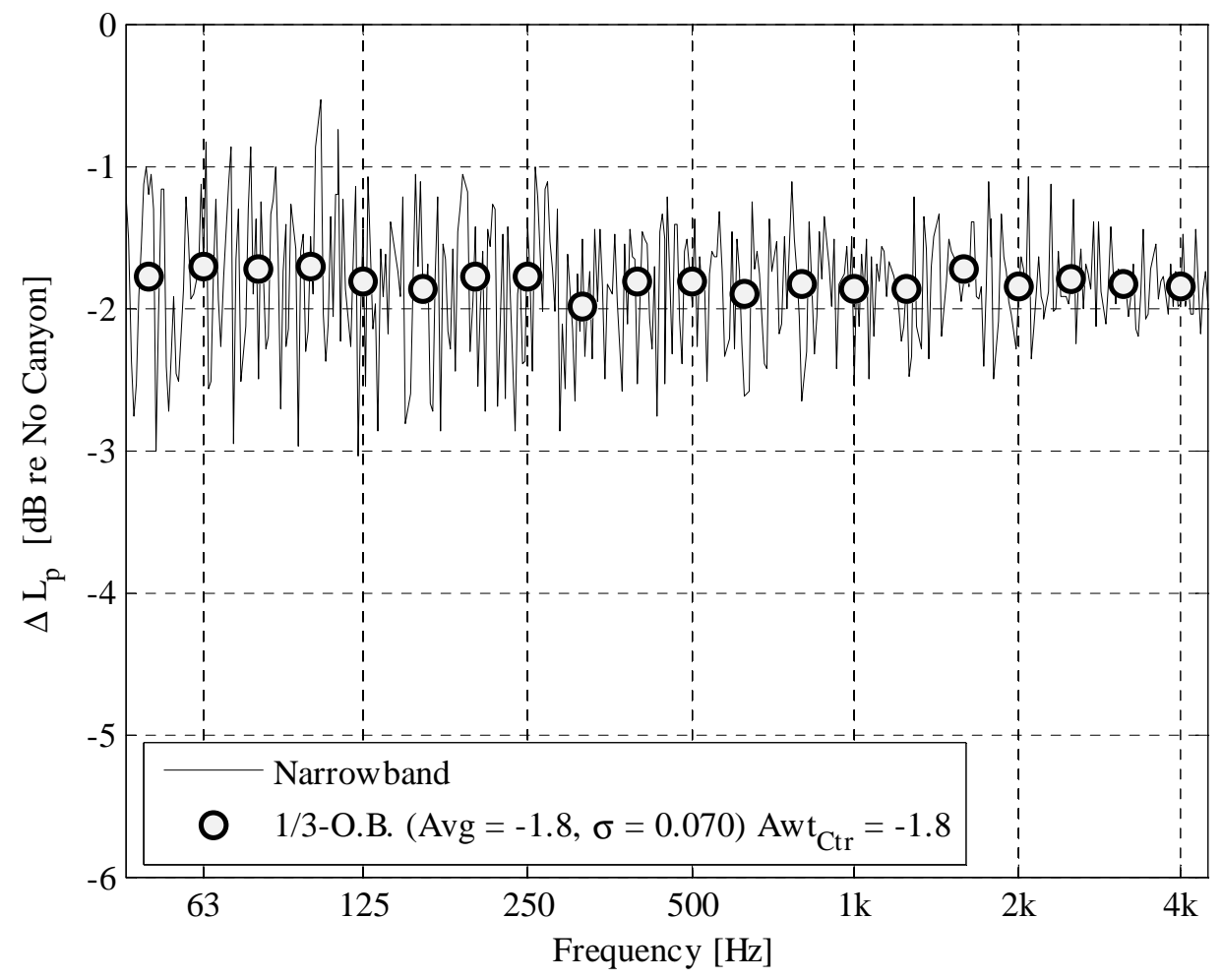

FIGURE 4 


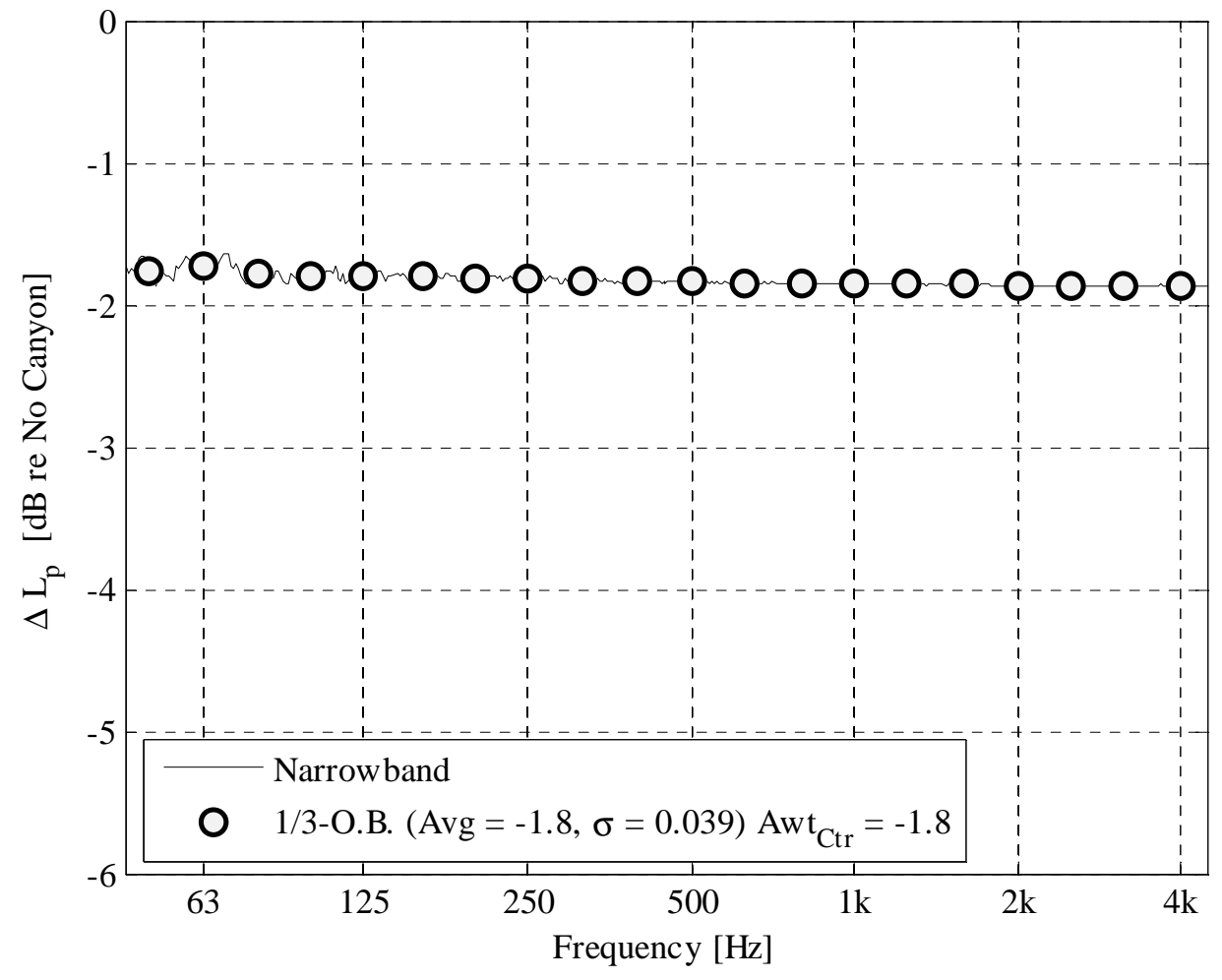

FIGURE 5 


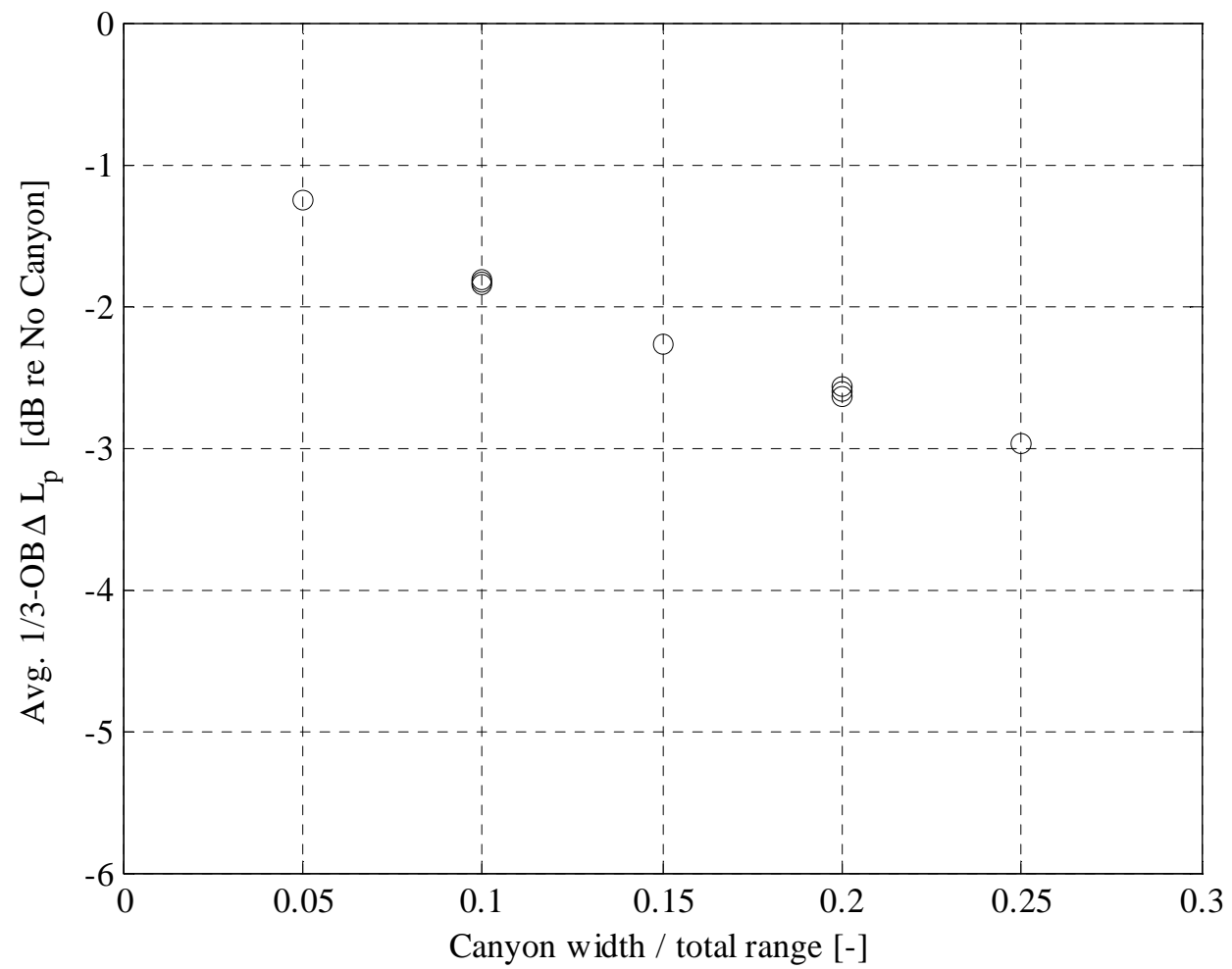

FIGURE 6 


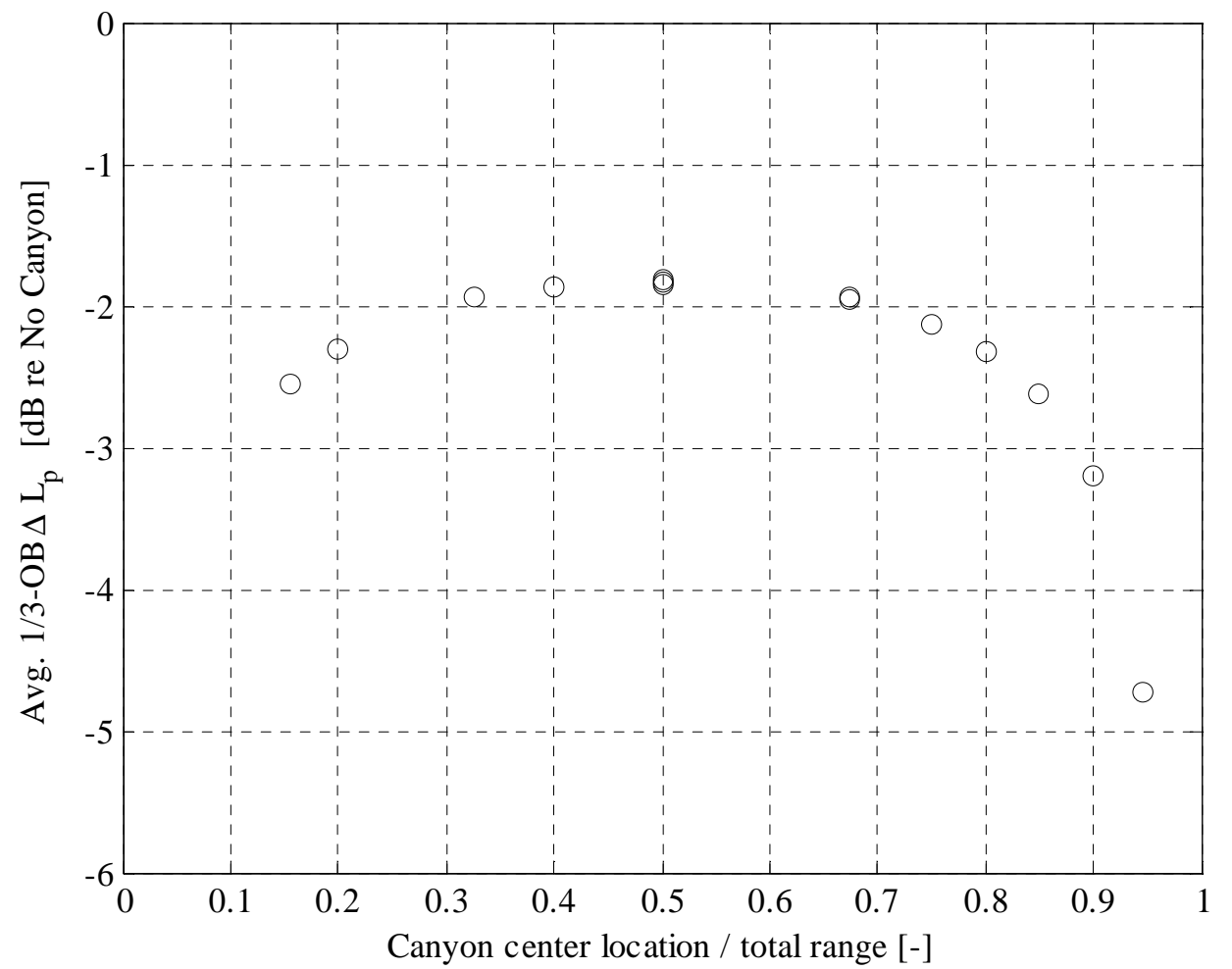

FIGURE 7 


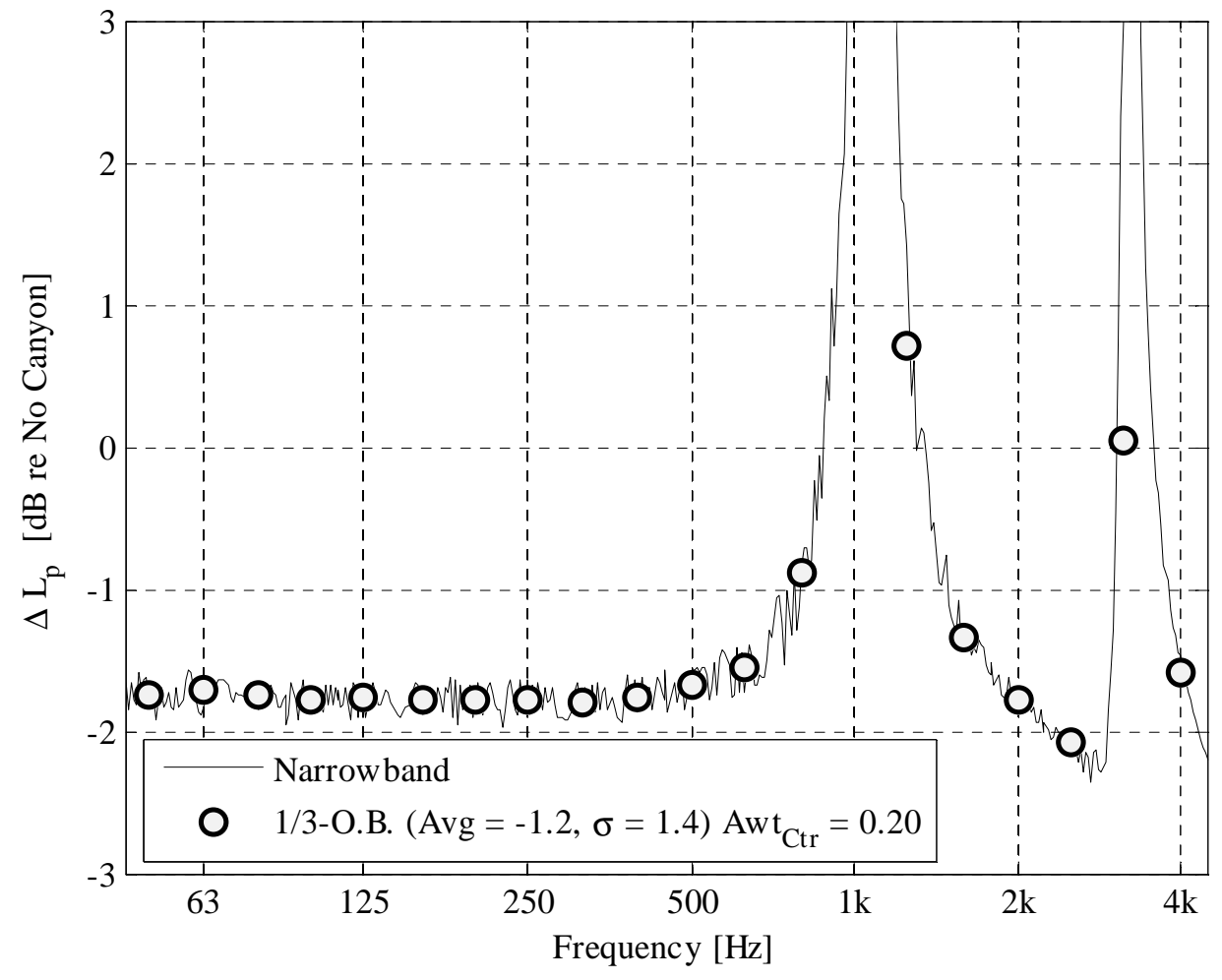

FIGURE 8 


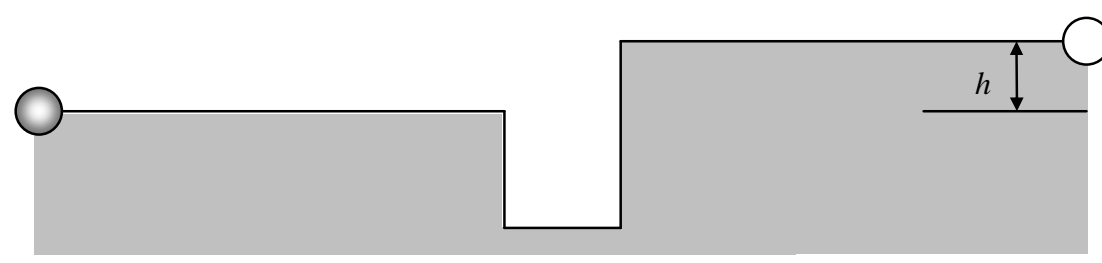

Roof-height difference, $h$

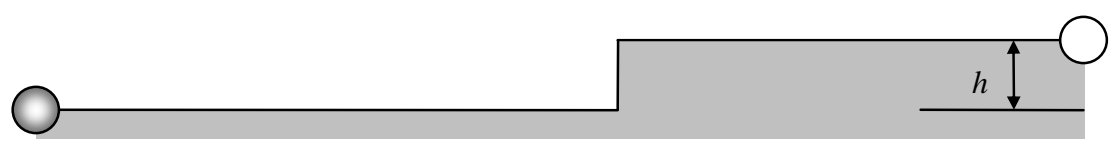

Reference "no canyon" case

FIGURE 9 


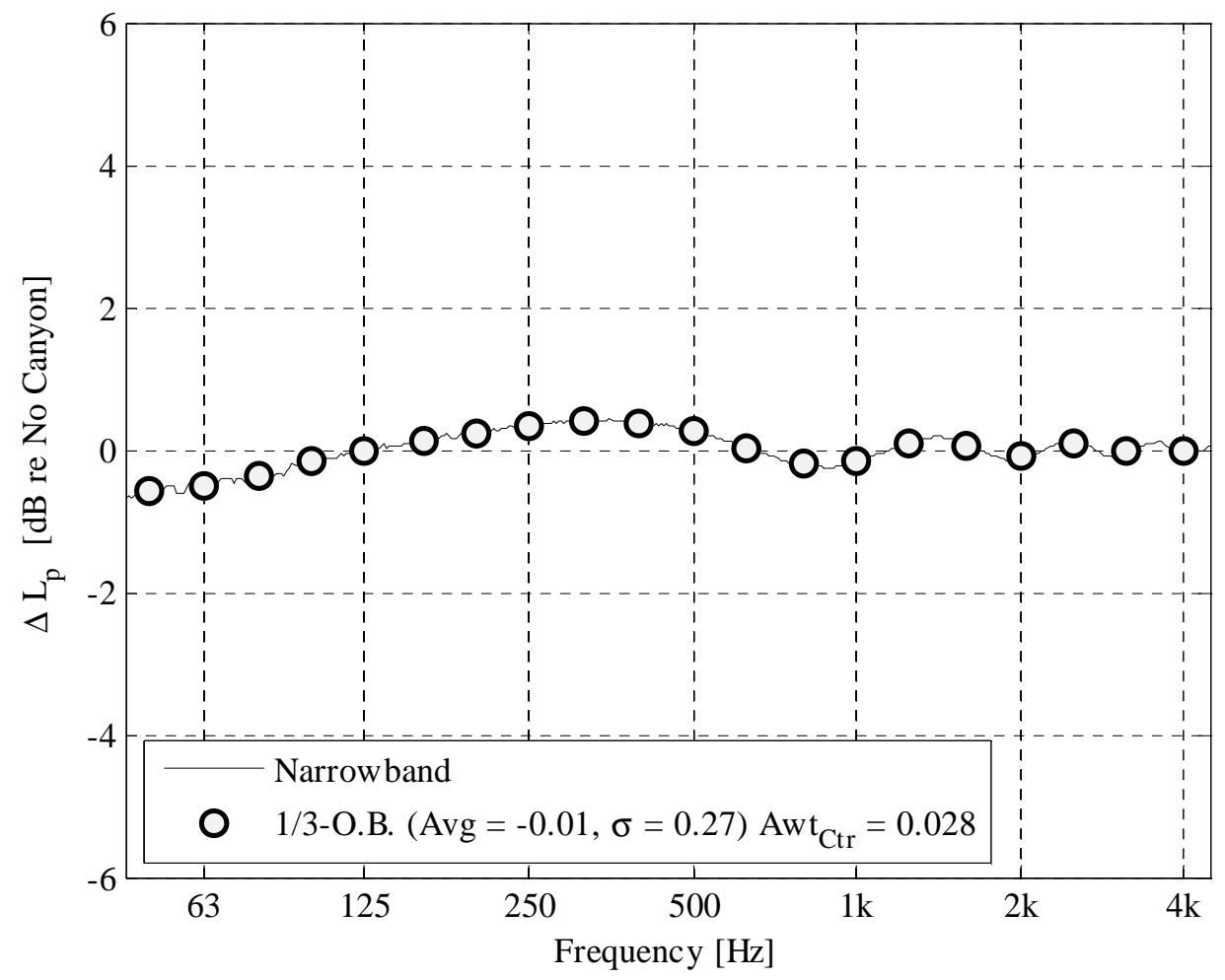

FIGURE 10 


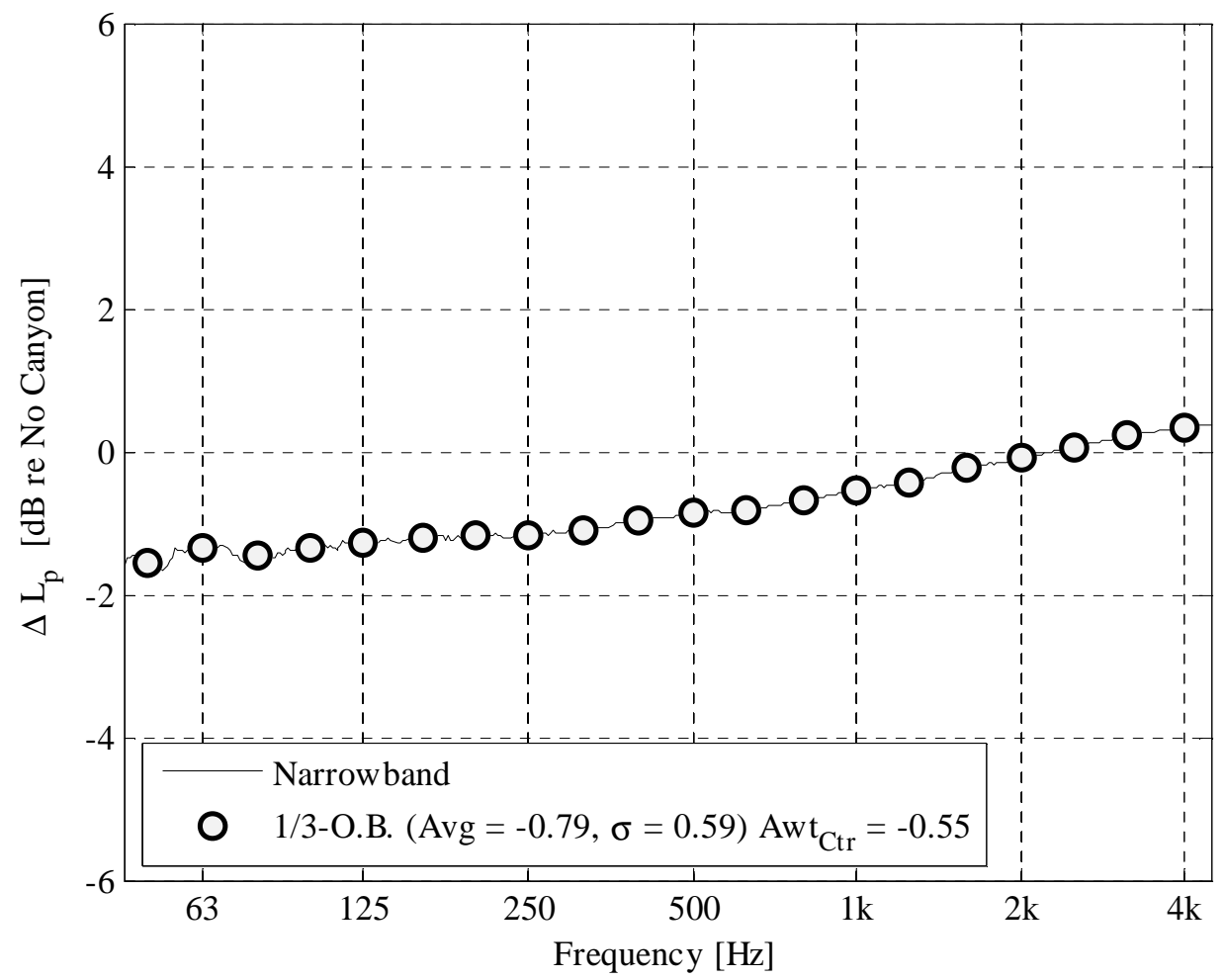

FIGURE 11 


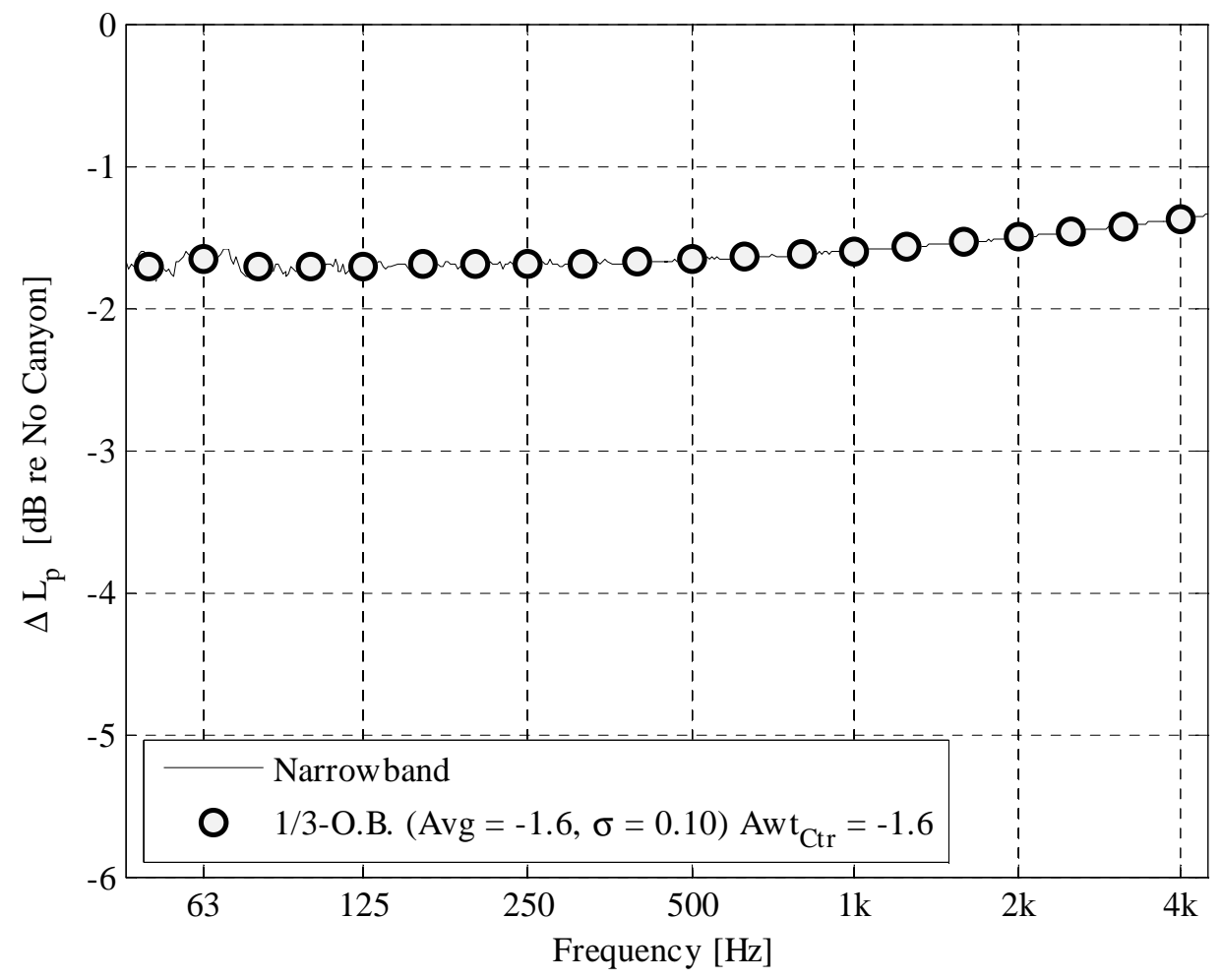

FIGURE 12 


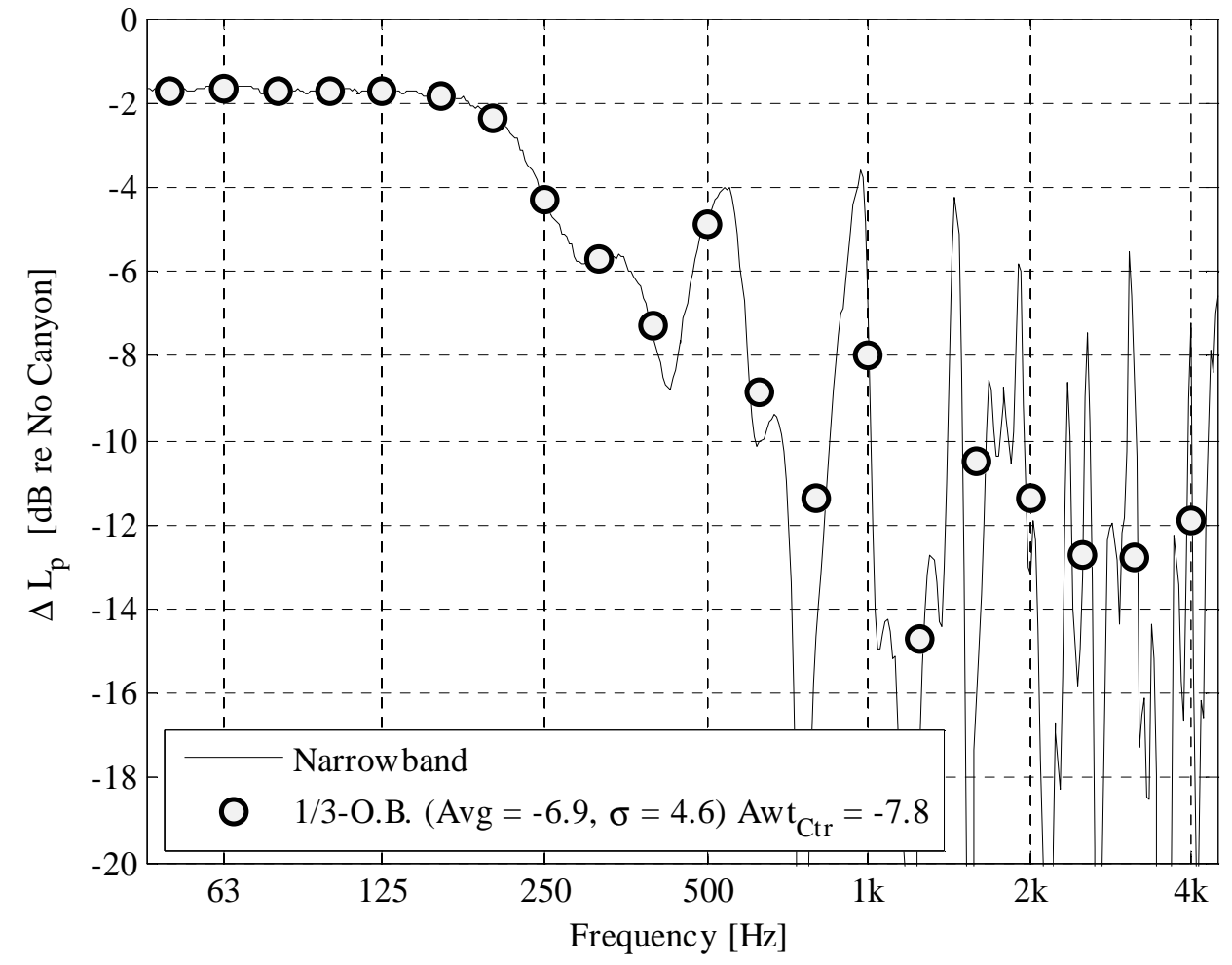

FIGURE 13 


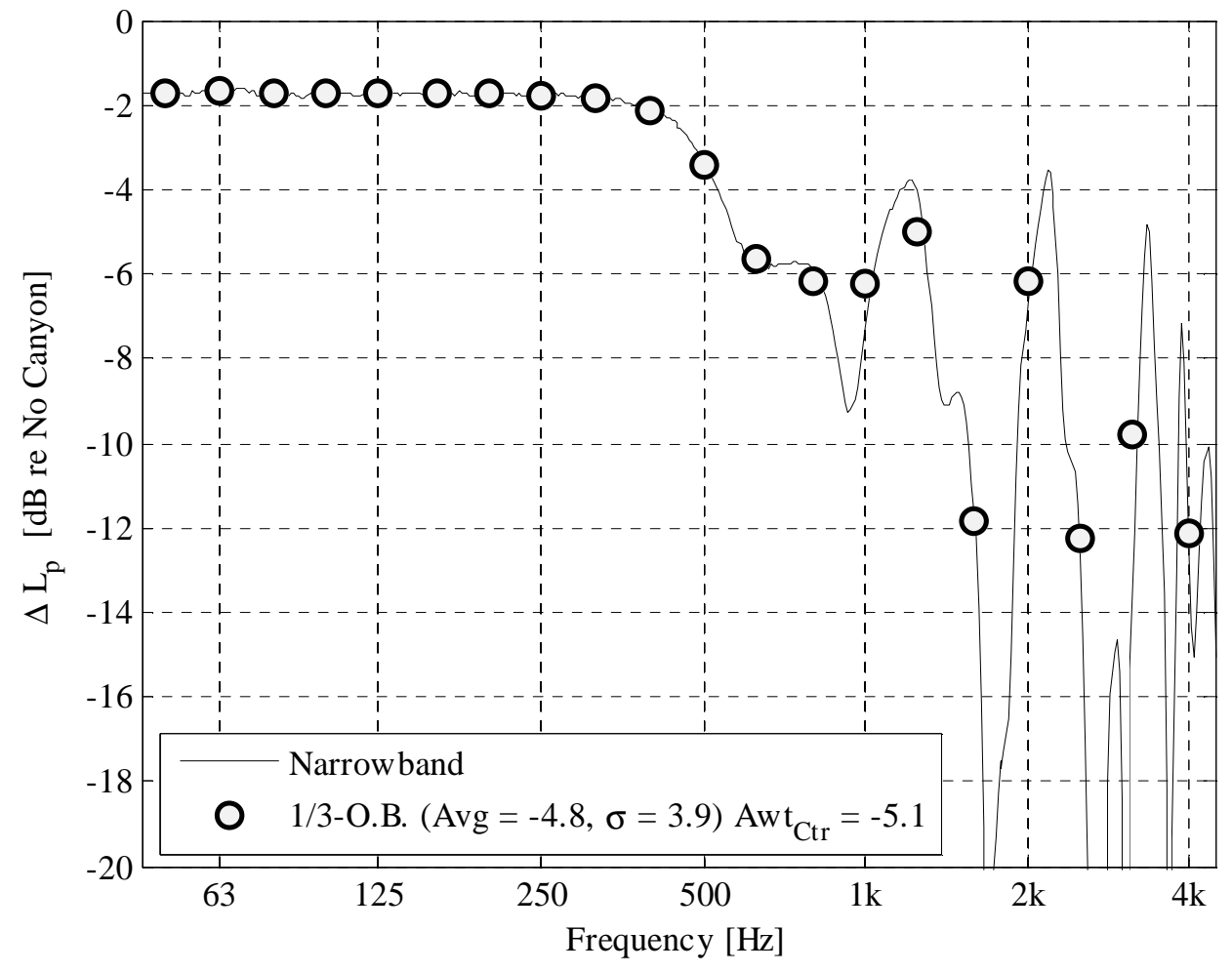

FIGURE 14 


\begin{tabular}{lll}
\hline Canyon Depth & Mean 1/3-O.B. EA [dB] & $\mathrm{Awt}_{\mathrm{Ctr}} \mathrm{EA}[\mathrm{dB}]$ \\
\hline $8 \mathrm{~m}$ & $-1.8(\sigma=0.10)$ & -1.8 \\
$20 \mathrm{~m}$ & $-1.8(\sigma=0.039)$ & -1.8 \\
$40 \mathrm{~m}$ & $-1.8(\sigma=0.043)$ & -1.8 \\
\hline
\end{tabular}

TABLE 1 


\begin{tabular}{llll}
\hline $\begin{array}{l}\text { Field } \\
\text { Length [m] }\end{array}$ & $\begin{array}{l}\text { Canyon } \\
\text { Location }[\mathrm{m}]\end{array}$ & $\begin{array}{l}\text { Mean 1/3-O.B. } \\
\text { EA [dB] }\end{array}$ & $\begin{array}{l}\mathrm{Awt}_{\mathrm{Ctr}} \text { EA } \\
{[\mathrm{dB}]}\end{array}$ \\
\hline 100 & $40-60$ & $-2.6(\sigma=0.067)$ & -2.6 \\
100 & $45-55$ & $-1.8(\sigma=0.060)$ & -1.8 \\
100 & $62.5-72.5$ & $-1.9(\sigma=0.058)$ & -2.0 \\
200 & $21-41$ & $-2.6(\sigma=0.081)$ & -2.6 \\
200 & $30-50$ & $-2.3(\sigma=0.063)$ & -2.3 \\
200 & $55-75$ & $-2.0(\sigma=0.042)$ & -2.0 \\
200 & $70-90$ & $-1.9(\sigma=0.043)$ & -1.9 \\
200 & $75-125$ & $-3.0(\sigma=0.049)$ & -3.0 \\
200 & $80-120$ & $-2.6(\sigma=0.043)$ & -2.7 \\
200 & $85-115$ & $-2.3(\sigma=0.040)$ & -2.3 \\
200 & $90-110$ & $-1.8(\sigma=0.039)$ & -1.8 \\
200 & $95-105$ & $-1.3(\sigma=0.043)$ & -1.3 \\
200 & $120-150$ & $-2.4(\sigma=0.045)$ & -2.5 \\
200 & $125-145$ & $-2.0(\sigma=0.043)$ & -2.0 \\
200 & $140-160$ & $-2.1(\sigma=0.046)$ & -2.2 \\
200 & $150-170$ & $-2.3(\sigma=0.051)$ & -2.3 \\
200 & $160-180$ & $-2.6(\sigma=0.060)$ & -2.7 \\
200 & $170-190$ & $-3.2(\sigma=0.079)$ & -3.2 \\
200 & $179-199$ & $-4.7(\sigma=0.22)$ & -4.8 \\
300 & $135-165$ & $-1.8(\sigma=0.033)$ & -1.9 \\
\hline
\end{tabular}

TABLE 2 


\begin{tabular}{llll}
\hline $\begin{array}{l}\text { Canyon ID/ } \\
\text { Combination }\end{array}$ & Canyon & Mean 1/3-O.B. & Awt $_{\mathrm{Ctr}}$ EA \\
\hline 1 & $55-75$ & EA $[\mathrm{dB}]$ & {$[\mathrm{dB}]$} \\
\hline $1+\mathrm{R} 1^{\mathrm{a}}$ & & $-2.0(\sigma=0.042)$ & -2.0 \\
& $-3.9(\sigma=0.080)$ & -3.9 \\
\hline${ }^{\mathrm{a}}$ Reciprocal location between source \& receiver. &
\end{tabular}

TABLE 3 


\begin{tabular}{llll}
\hline $\begin{array}{l}\text { Canyon ID/ } \\
\text { Combination }\end{array}$ & $\begin{array}{l}\text { Canyon } \\
\text { Location [m] }\end{array}$ & Mean 1/3-O.B. & $\begin{array}{l}\text { Awt }_{\mathrm{Crr}} \text { EA } \\
{[\mathrm{dB}]}\end{array}$ \\
\hline 1 & $21-40$ & $-2.4(\sigma=0.074)$ & -2.4 \\
2 & $70-90$ & $-1.6(\sigma=0.040)$ & -1.6 \\
3 & $130-140$ & $-0.93(\sigma=0.027)$ & -0.94 \\
4 & $160-185$ & $-1.5(\sigma=0.024)$ & -1.5 \\
$1+2+3+4$ & & $-6.0(\sigma=0.14)$ & -6.1 \\
$1+2+3+4+$ & & & \\
$\quad \mathrm{R}^{\mathrm{a}}+\mathrm{R} 3+\mathrm{R} 2+\mathrm{R} 1$ & & $-12(\sigma=0.24)$ & -12 \\
\hline
\end{tabular}

${ }^{\mathrm{a}}$ Reciprocal location between source $\&$ receiver.

\section{TABLE 4}

